\title{
DEBATE
}

\section{concept stretching: the case of deliberation}

jürg steiner ${ }^{a, b}$

aUniversity of North Carolina at Chapel Hill, Chapel Hill, NC, USA

E-mail: jsteiner@email.unc.edu

bUniversity of Bern, Untere Wart 30, 3600 Thun, Switzerland

doi:10.1057/palgrave.eps.2210186

\section{Abstract}

Sartori (1970) warned a long time ago of the danger of concept stretching for effective and cumulative theory building. Such concept stretching has happened with regard to deliberation, which has become a very faddish term. For theoretically well-founded empirical research it is better conceptually to distinguish clearly between strategic bargaining and deliberation, although in the empirical political world the two concepts are usually heavily intertwined.

Keywords deliberation; concept stretching; strategic bargaining

$\mathrm{T}$

he concept of deliberation has become so faddish that it is in danger of being 'stretched' until it becomes virtually a synonym for talk of any kind. A long time ago, Sartori (1970) warned of the dangers of concept stretching in political science, and this warning is still valid. Based on Sartori's work, Collier and Levitsky (1997) have also prominently written about the danger of concept stretching, in their case specifically in relation to the concept of democracy. One encounters the problem not only with regard to deliberation but also with many other concepts used in political science.

There are certainly different versions of the concept of deliberation. But as Goodin (2005: 183) points out, on the basis of a review of the literature: 'As regards standards for what counts as "good" discourse and deliberation, there seems to be an impressively broad scholarly consensus'. Deliberation does not simply mean talk of any kind; the concept has a very specific meaning. For fruitful and rigorous research, this specificity must be kept. If the concept is stretched too far it begins to mean everything and therefore nothing.

A particularly extreme example of concept stretching with regard to deliberation is a paper by Austen-Smith and Feddersen (2006). I use this example as a useful illustration to make my point, although there are other examples where I could make the same point (Steiner et al, 2004: 43-52). Austen-Smith and Feddersen use the concept in its very opposite meaning from the standard usage in the deliberative literature. They present a formal 
mathematical model in which they establish theoretically under what conditions members of political committees are willing to share private information with other committee members. Their example is a jury consisting of three members, who have to choose whether to acquit or to convict a defendant. Two jury members are cautious and wish to have at least three pieces of evidence of guilt to convict; the third jury member is less cautious and considers one piece of evidence of guilt as sufficient to convict. The question is under what conditions the jury members are willing to share their private information on guilt with the other jury members. The assumption is that when it serves their individual preferences, jury members share such information, when it does not, they withhold the information since in these cases 'there is no downside risk of lying' (p. 211). The specific research question is whether such lying occurs more often under majority rule or rule of unanimity. The model of Austin-Smith and Feddersen predicts that lying is more likely under unanimity than under majority rule. We are not concerned here with the content of this hypothesis. Our interest is rather in why they use the concept of deliberation throughout their paper and even in its title.

Austen-Smith and Feddersen cite two works of the deliberative literature, so evidently they are aware of this literature. Their usage of the concept of deliberation is therefore not a harmless error or a result of inattentiveness. I will now argue that they stretch the concept in a way that is 'beyond-the-pale'. One key element of the deliberative model is that actors do not lie but are truthful and authentic in their statements. According to Habermas (1983: 98), 'each speaker may only assert what he believes himself'. This criterion of truthfulness means that all participants are open about their true preferences and do not try to deceive and mislead others. Put in another way, participants really mean what they say. When they refer to particular values such as social justice, they truly believe in these values and do not utter them merely for tactical reasons to increase their chances to win with their own preferences.

Perhaps most politicians are indeed not truthful and lie whenever it serves their preferences. Therefore, it can certainly be a useful exercise to model such situations, and I have no objection to such modelling. But Austen-Smith and Feddersen would do better not to use deliberation for such situations, since the concept has a specific meaning in political philosophy. Its core is that political actors should be willing to change their preferences by the force of better argument in truly listening to the points of view of others. To quote Habermas (1996: 305), actors should be open to the unforced force of the better argument'. What the better argument is, is not a priori given, but must be searched for in common discourse. It is through such discourse that participants find out what counts as a good argument. The model of AustenSmith and Feddersen violates this key assumption of the deliberative model in an extreme way. During the simulated jury session, the three members do not change their preferences on how much information on guilt is necessary for conviction. Their preferences are assumed to be fixed. No exchange of arguments takes place.

I am aware that in other formal models, preferences may be changed on the basis of new information or a new choice environment (Gilligan and Krehbiel, 1990). The assumption in such models is that only ultimate preferences are fixed. If it turns out that currently held preferences are in contradiction with these ultimate preferences, it is rational to correct the error and to change the currently held preferences so that they 
become compatible with the ultimate preferences. In this way, formal models come closer to the deliberative model in the sense that actors are willing to consider information procured by other actors. The ultimate preferences, however, are never changed by the force of the better argument. In the model of Austen-Smith and Feddersen, no change of preferences is assumed, not even at a lower level of abstraction. The three jury members stick to their preferences with regard to the amount of evidence of guilt necessary for conviction. Therefore, the concept of deliberation seems particularly inappropriate. Austin-Smith and Feddersen are, of course, entitled to use concepts however they wish. But it would be helpful for the scholarly community if they would label the talk that is going on in their model as strategic bargaining, which seems a more appropriate term for what happens in their model.

There are other important elements of the deliberative model that are completely missing in the paper of Austen-Smith and Feddersen. According to the deliberative literature, claims must be extensively justified with logical reasons and supporting evidence. The merits of an argument need to be expressed not merely considering one's own interests but also the interests of others. Participants must treat each other with genuine respect. Taking all these elements together, deliberation is a rather complex concept, and it should be used with care. In what sense exactly do Austen-Smith and Feddersen stretch the meaning of deliberation? When members of a political committee, in their case a jury, share information only when it serves their individual preferences, it is strategic talk in a pure form. In order to reach one's preferences, actors lie whenever it serves their individual purposes. There is no concern and respect for the preferences and arguments of others. What counts are only one's own preferences. To attain

\section{'deliberation is a rather complex concept, and it should be used with care'}

these preferences, actors do anything, including lying. In a nutshell, political actors are assumed to be individual utility maximisers.

I grant that such utilities may refer in some more sophisticated formal models not only to narrow self-interest such as being elected or making money but also to the common good. But what the common good is, is defined on an individual basis. An actor has a personal preference of how the common good should look like. How others define the common good is not relevant. Even in such sophisticated models there is no exchange of arguments about the best possible form of the common good. In the model of Austen-Smith and Feddersen no reference at all is made to the common good. The preferences of the three jury members with regard to the amount of evidence of guilt needed for conviction is simply assumed without any justification with regard to the common good or other moral values. The preferences are external to the model, and the actors in the model do not give any arguments as to why they hold these preferences. In the deliberative model, by contrast, actors are assumed to give elaborate reasons for their preferences.

There is now an increasing literature on empirical studies of deliberation where the concept is defined in a manner consistent with its meaning in philosophy. ${ }^{1}$ Empirical measures have been developed with high reliability and validity to establish the level of deliberation, which has enabled testing hypotheses about the antecedents and consequences of variation in the level of deliberation. We should be aware that the deliberative model is a Weberian ideal type. The real world of politics hardly ever corresponds fully to 
this ideal type. Habermas (1996: 323) acknowledges that

(e)ven under favorable conditions, no complex society could ever correspond to the model of purely communicative social relations ... rational discourses have an improbable character and are like islands in the ocean in everyday praxis.

Given the ideal-typical formulation of the deliberative model, the empirical research task is to establish how far away a particular speech situation is from the ideal type. Such research has been done in particular for international negotiations, debates in national parliaments, discussions among ordinary citizens, local politics, non-governmental organisations, internet communication. To establish the level of deliberation in these different settings, a wide variety of research methods has been used: participant observation, focus groups, experiments, analysis of transcripts, interviews. ${ }^{2}$ The formal model of Austen-Smith and Feddersen is as far away from the deliberative ideal type as one can imagine. Indeed, it contains not a single deliberative element but is exclusively built on strategic action. Therefore, to label the talk taking place in their model as deliberative is troubling from a conceptual point of view.

There is increasing collaboration on deliberation between philosophers and empirically oriented scholars. As Habermas (2005: 385) puts it, 'philosophical analysis (on deliberation) assumes more and more features of an empirical research'. At the philosophical level, there are many conflicting hypotheses about the antecedents and consequences of a high level of deliberation, for example whether public meetings or close-door meetings are more conducive to a high level of deliberation or whether rules of unanimity or majority rules make deliberation more likely. Empirical studies help to sort out such hypotheses. Rosenberg
'Empirical measures have been developed with a high reliability and validity to establish the level of deliberation'

'the rational choice model can certainly much better predict how the price of oil on international markets is set; but perhaps the deliberative model is better when it comes to Aids policies on a world scale'

(2007) has edited a volume where empirical scholars present their research on deliberation and then philosophers discuss the impact of this research on the future philosophical debate on deliberation. This debate about the interplay of empirical and philosophical research on the deliberative model is confounded if scholars liked Austen-Smith and Feddersen use the concept of deliberation in a way that has nothing to do with the way it is used in democratic theory. Deliberative theorists are very careful as to how they define their concepts. Stretching the concept of deliberation as Austen-Smith and Feddersen do, leads to theoretical vacuity and practical confusion.

Finally, I wish to argue that it is not merely a question of terminology as to how we use the concept of deliberation. It also matters substantively as to how we approach at a very fundamental level our research enterprise in political science. We may try to integrate the rational choice model and the deliberative model into an overall super model. Although such a super model may be a long-term 
goal, in my view, it is better to keep the two models separate since they are based on diametrically opposed views of basic human nature. Both models allow the formulation of predictions about the political world, and one can then establish which model is a better fit with empirical reality. If we take the international field, the rational choice model can certainly much better predict how the price of oil on international markets is set; but perhaps the deliberative model is better when it comes to Aids policies on a world scale. In the domestic field, the deliberative model may be more appropriate to countries with power sharing institutions than those based on the Westminster model (Steiner et al, 2004). Furthermore, the deliberative model may do better in the early stages of a decision process whereas the rational choice model may be superior in the later stages. It is an exciting research agenda to compare in a systematic way how the predictions derived from both the rational choice model and the deliberative model perform in the real world of politics. Such a research agenda will also help to build bridges in the discipline. $A$ precondition is that we are careful of how we use our concepts. Sartori was correct that good research begins with clear conceptualisations.

\section{Notes}

1 See the two special issues of Acta Politica on Empirical Approaches to Deliberative Politics, Volume 40, numbers 2 and 3, 2005. See also the papers in the workshop on deliberation, ECPR Joint Workshops, Helsinki, 7-12 May 2007.

2 See literature in note 1.

\section{References}

Austen-Smith, D. and Feddersen, T.J. (2006) 'Deliberation, preference uncertainty, and voting rules', American Political Science Review 100(2): 209-218.

Collier, D. and Levitsky, S. (1997) 'Democracy with adjectives: conceptual innovation in comparative research', World Politics 49(3): 430-451.

Gilligan, T. and Krehbiel, K. (1990) 'Organization of informative committees by a rational legislature', American Journal of Political Science 34: 531-564.

Goodin, R.E. (2005) 'Sequencing deliberative moments', Acta Politica 4(2): 182-196.

Habermas, J. (1983) Moralbewusstsein und kommunikatives Handeln, Frankfurt a. M.

Habermas, J. (1996) Between Facts and Norms. Contributions to a Theory of Law and Democracy, Cambridge, MA: MIT Press.

Habermas, J. (2005) 'Concluding comments on empirical approaches to deliberative politics', Acta Politica 40(3): 384-392.

Rosenberg, S.W. (ed.) (2007) Deliberation, Participation, and Democracy, London: Palgrave Macmillan.

Sartori, G. (1970) 'Concept misformation in comparative politics', American Political Science Review 64(4): 1033-1053.

Steiner, J., Bächtiger, A., Spörndli, M. and Steenbergen, M.R. (2004) Deliberative Politics in Action. Analyzing Parliamentary Discourse, Cambridge: Cambridge University Press.

\section{About the Author}

Jürg Steiner is professor emeritus at the University of North Carolina at Chapel Hill and the University of Bern. In 2003-04 he held the Swiss Chair at the European University Institute in Florence. Recent book include Deliberative Politics in Action (Cambridge University Press, 2004) and European Democracies (Longman, 2007). 